\title{
Aa. Vv., «Cahiers Octave Mirbeau», $n^{\circ} 16$
}

\section{Ida Merello}

\section{(2) OpenEdition}

\section{Journals}

\section{Edizione digitale}

URL: http://journals.openedition.org/studifrancesi/7680

DOI: 10.4000/studifrancesi.7680

ISSN: 2421-5856

\section{Editore}

Rosenberg \& Sellier

\section{Edizione cartacea}

Data di pubblicazione: 1 décembre 2009

Paginazione: 659

ISSN: 0039-2944

\section{Notizia bibliografica digitale}

Ida Merello, «Aa. Vv., «Cahiers Octave Mirbeau», n¹6», Studi Francesi [Online], 159 (LIII | III) | 2009, online dal 30 novembre 2015, consultato il 09 janvier 2021. URL: http://journals.openedition.org/ studifrancesi/7680 ; DOI: https://doi.org/10.4000/studifrancesi.7680

Questo documento è stato generato automaticamente il 9 janvier 2021.

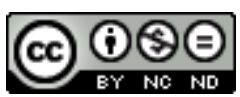

Studi Francesi è distribuita con Licenza Creative Commons Attribuzione - Non commerciale - Non opere derivate 4.0 Internazionale. 


\title{
Aa. Vv., «Cahiers Octave Mirbeau», $\mathrm{n}^{\circ} 16$
}

\author{
Ida Merello
}

\section{NOTIZIA}

«Cahiers Octave Mirbeau», n¹6, 2009.

1 Questo «Cahier» comprende dodici studi, oltre a un certo numero di documenti e una larga sezione bibliografica e di note di lettura. In apertura, Pierre MICHEL commenta la presenza di alcuni personaggi che ricorrono in più opere di Mirbeau, tuttavia nega ogni similitudine coi personaggi ricorrenti della Comédie humaine, perché Mirbeau non condivide il desiderio di ampliare l'affresco sociale al di là del suo orizzonte. Yannick LEMARIÉ ci propone una curiosa lettura dell' Abbé Jules attraverso il mito di Edipo sottratto agli elementi psicanalitici e colto nei soli aspetti formali della menomazione post natale, in relazione al motivo del parto e dell'uso del forcipe presente nel romanzo. Robert ZIEGLER legge il Journal d'une femme de chambre come un'archeologia della coscienza mirbelliana in cammino verso la tolleranza, perciò considera gli atteggiamenti violenti dei personaggi di Mirbeau come residui dei suoi stessi pregiudizi e vede lo scrittore scettico nei confronti del raggiungimento di qualsiasi equilibrio ideale, al di sotto del quale deve nascondersi necessariamente un'impostura. Secondo l'A. perciò Mirbeau esplora le nevrosi come i romanzieri naturalisti, senza peraltro cercare diagnosi, che significherebbero un tentativo di riportare l'ordine. Claude HERZFELD avrebbe dovuto essere inserito negli atti sulla E628-E8, perché ritorna sul viaggio di Mirbeau stabilendo un confronto tra la critica d'arte dello scrittore e quella di Fromentin. Christian LIMousin prosegue il discorso sulla critica d'arte, mostrando l'importanza dell'influenza di Monet, che insegnò a Mirbeau ad apprezzare sia Courbet che le stampe giapponesi, ricorda la sua antipatia per Moreau, il rapporto con Rodin, la stima per Marie Bashkirtseff. Arnaud VAREILLE analizza l'atteggiamento di Mirbeau nei confronti del linguaggio, contemporaneamente mezzo di rivelazione e strumento 
improprio, concentrandosi sul rapporto tra cronaca e finzione, in particolare sulla creazione dell'intervista e dei dialoghi immaginari, che fa risalire all'aprile 1887 nell'ambito delle cronache d'arte. L'A. vi vede un modo ironico di fare letteratura, con una serie di contrassegni finzionali tipici e atipici, ma ricorda come la maggior parte dei testi di impegno per Dreyfus siano di finzione, a riprova che la finzione è anche un modo di «mentir vrai», e di dare più forza alle proprie idee. Samuel LAIR documenta $\mathrm{i}$ rapporti tra Mirbeau e Geoffroy attraverso la corrispondenza tra i due scrittori; mentre Sonia ANTON si interessa alla corrispondenza generale; Antigone SAMIOU ci presenta la fortuna di Mirbeau in Grecia e Jean-Claude DELAUNEY pubblica il catalogo della sua biblioteca. 